

\section{DISCLAIMER}

This report was prepared as an account of work sponsored by an agency of the United States Government. Neither the United States Government nor any agency Thereof, nor any of their employees, makes any warranty, express or implied, or assumes any legal liability or responsibility for the accuracy, completeness, or usefulness of any information, apparatus, product, or process disclosed, or represents that its use would not infringe privately owned rights. Reference herein to any specific commercial product, process, or service by trade name, trademark, manufacturer, or otherwise does not necessarily constitute or imply its endorsement, recommendation, or favoring by the United States Government or any agency thereof. The views and opinions of authors expressed herein do not necessarily state or reflect those of the United States Government or any agency thereof. 


\section{DISCLAIMER}

Portions of this document may be illegible in electronic image products. Images are produced from the best available original document. 
Issued by Sandia Laboratories, "1puta ated for the United States Energy Research \& Development Administratiun by Sandia Corporation.

\section{NOTICE}

This report was prepared as an account of work sponsored hy the United States Government. Neither the United States nor the United States Energy Research \& Development Administration, nor any of their employees, nor any of their contractors, subcontractors, or their employees, makes any warranty, express or implied, or assumes any legal liability or responsibility for the accuracy, completeness or usefulness of any informatiun, apparatus, product or process disclosed, or represents that its use would not infringe privately owned rights.

Printed in the United States of America Available from

National Technical Information Service

U. S. Department of Commerce

5285 Port Royal Road Springfield, VA 22161

Price: Printed Copy $\$ 4.50$; Microfiche $\$ 3.00$ 
SAND77-0357

Unlimited Release

Printed July, 1977
This report was preptice

This report was prepared as an account of work sponsored by the United States Government. Neither Rescarch and Development Adniled States Energy their employess. nor any of their " nor any of subcontractors, or their employees, makes any wamanty, express or implied, or assuries any legal Lisuly or responsibuity for the accuracy, completeness processess or any information, apparatus, product or infringe privitedy. or represents that its use would not

SHORT-TERM ANNEALING IN SILICON DEVICES AFTER

FISSION AND FUSION NEUTRON IRRADIATIONS

\author{
J. M. McKenzie* \\ Advanced Facilities Protection Division - 1751 \\ Sandia Laboratories, Albuquerque, New Mexico 87115
}

\begin{abstract}
The described technique estimates the transient recovery of a semiconductor device to a short pulse of damaging radiation. Unlike previous techniques this method uses meaningful parameters, at relevant fluences, of typical mil. spec. devices. Using existing simulation facilities steady state (seconds) irradiations are proposed and a Fredholm integrul equation is unfolded to obtain the transient response. The technique, which is applicable to both neutron and gamma radiation, is demonstrated by a simulated neutron irradiation transient recovery experiment. Applied to weapons systems the technique facilitates accurate predictions of elestronic recovery times after exposure of the system to a weapons burst. It also obviates the necessity of building new pulsed simulation machines for direct measurement of transient recovery.
\end{abstract}

* Formerly with Program Develupment Division - 5433 


\section{ACKNOWLEDGEMENTS :}

The author gratefully acknowledges the help of Dr. F. Biggs in formulating the mathematical model, and of H. H. Sanders and D. C. Evans for discussions of transient annealing. 
CONTENTS

$\underline{\text { Page }}$

I. Introduction . . . . . . . . . . . . . . 5

II. Proposed Experiments . . . . . . . . . . . . . . II

III. Prediction Analysis . . . . . . . . . . . . . I5

IV. Dosimetry . . . . . . . . . . . . . . 36

V. Irradiation Facilities . . . . . . . . . . . 37

VI. Electronic Measurements . . . . . . . . . . 37

VII. Conclusions ................... . 41 


\section{ILLUSTRATIONS}

Figure

1. Transient Annealing for $\delta$ Functions of Neutrons

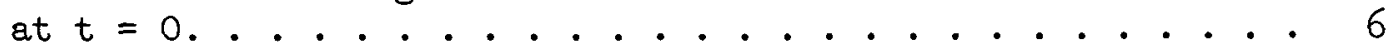

2. Transient Annealing Fission \& Fusion Neutrons (Srour \& Curtis). . . ................ 10

3. Transient Response after Exposure tu $\delta$ Function of Neutrons . . . . . . . . . . . . . . . . 12

1. Transient, Response after Exposure to DC Function of Neutrons . . . . . . . . . . . . . . . . . . . 13

b. Experlmenlal Configuration for Transient Annealing Experiments . . . . . . . . . . . . . . . . . . . 17

6. Transient Response of Drain Current to $\delta$ Function of Neutrons . . . . . . . . . . . . . . . . . . 23

7. Transient Response Following Square Wave Irradiation. . . . 29

8. Test Circuits for JFETS . . . . . . . . . . . . . 38

9. Test Circuit for Bipolar Transistors. . . . . . . . . . 39

10. Block Diagram of Electronic Measuring Circuits. . . . . . : . 40.

TABLES

Number

$\underline{\text { Page }}$

1. Assignments Made to 5 Transistors . . . . . . . . . . 19

2. Simulated Measurements of 5 Transistors $\delta$ Function Irradiation . . . . . . . . . . . . . . . . . . 22

3. Statistics of Quadratic B Spline Fit to the Simulated Experimental Data for \#I Transistor $\delta$ Function Case 24

4. Solution Data $y(t)$ of Quadralic B Upline Fit to the Simulated Experimental Data for \#l Transistor . . . . . . . . 25

5. Input Data and Solution Comparison for $\delta$ Function Irradiation . . . . . . . . . . . . . . . . . . . . 27

6. Simulated Measurements of 5 Transistors, Long Irradiation . . 31

7. Statistics of a Quadratic B Spline Fil lo lintegral Equations for \#I Transistor dc Case . . . . . . . . . . . 33

8. Estimate for $f(\omega)$ From Quadratic B Spline Solution of Integral Data . . . . . . . . . . . . . . . 34

9. Input Data \& Solution Comparison for Long Irradiation . . . 35 


\title{
SHORT-TERM ANNEALING IN SILICON DEVICES AFTER FISSION AND FUSION NEUTRON IRRADIATIONS
}

\author{
J. M. Mckenzie \\ Program Development Division \\ Sandia Laboratories, Albuquerque, NM 87115
}

\section{Introduction}

Neutron irradiation of a silicon semi-conductor device causes a deterioration of the device parameters. This degradation is usually characterized by a long-term or permanent change in the device parameters. The change is not only proportional to the neutron fluence but also depends, in a complicated way, on the energy spectral distribution of the neutrons. The latter problem has been addressed many times. A computer code is now available* which, given certain experimental information, estimates the amount of long-term degradation for any given spectral fluence of neutrons relative to that of a given simulation fluence.

Superposed on the long-term or permanent degradation is a transient degradation. This is often defined by an annealing factor. Thus, for a device parameter $y$ in Figure 1, the annealing factor[1] at a time $\tau$ is given by:

$$
\text { A.F. }(t=\tau)=B / A \text {, }
$$

where the device was exposed to a very short burst of neutrons at $t$ ime $t=0$.

\footnotetext{
*Program EQUIV available from J. M. McKenzie, Sandia Laboratories Albuquerque, NM 87115
} 


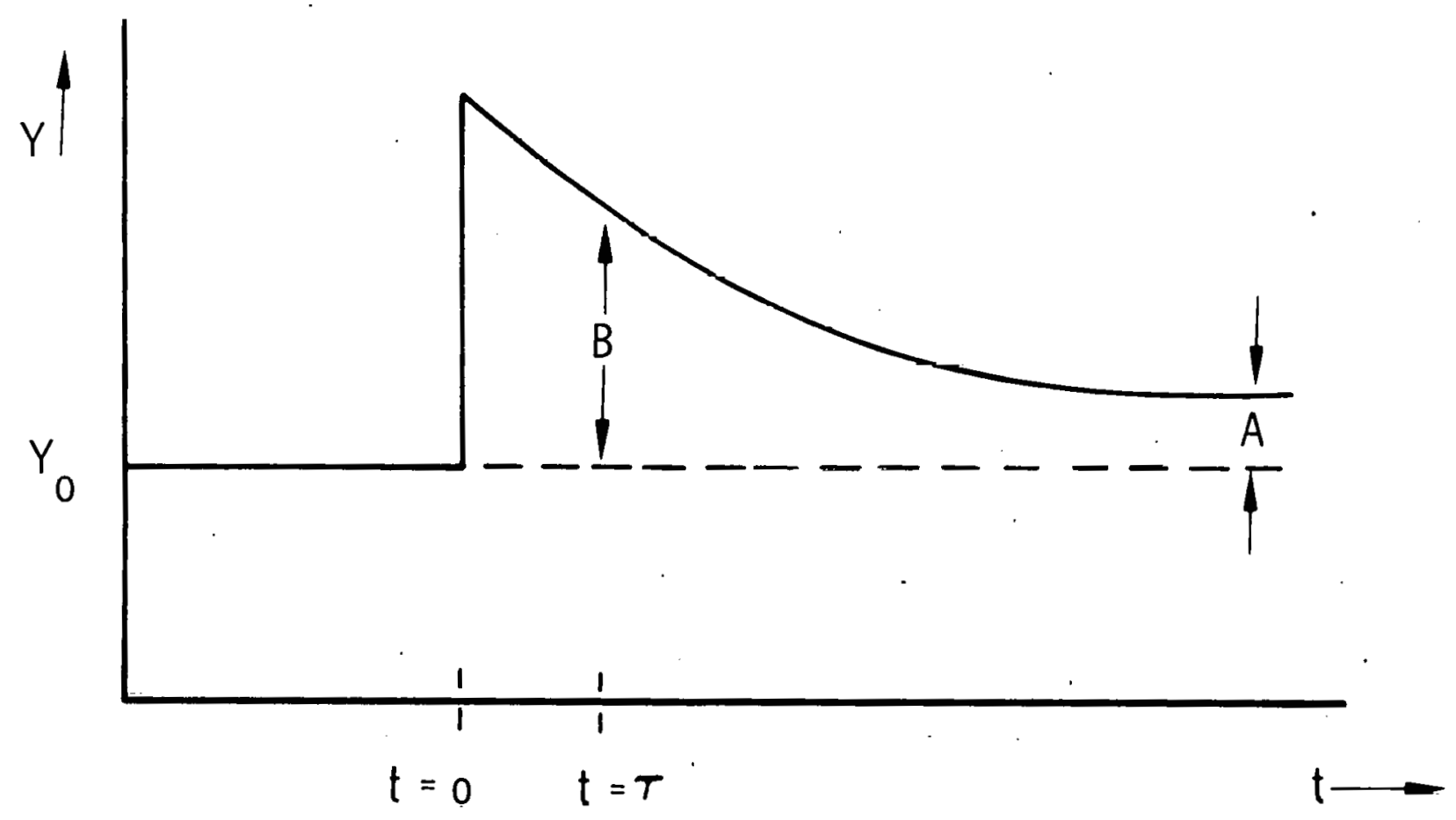

Figure 1. Transient Annealing for $\delta$ Functions of Neutrons at $t=0$. 
Alternatively, the device response may be described for a short burst of fission neutrons by:

$$
y_{\text {fiss }}(t)=y_{0}+\operatorname{TS} \Phi_{\text {fiss }}\left\{1+f_{\text {fiss }}(t)\right\} \text {, }
$$

where

$$
\begin{aligned}
& \Phi_{\text {fiss }} \text { is the fission fluence at } t=0 \text {; } \\
& \text { TS is a constant and gives the permanent change } \\
& \text { in } y \text { due to unit fluence; } \\
& \mathrm{f}_{\text {fiss }}(\mathrm{t}) \text { is a transient decay function: } \\
& \text { and } y_{0} \text { is the pre-irradiation value of } y \text {. }
\end{aligned}
$$

A similar curve can be described for a short burst of fusion neutrons. That is:

$$
Y_{\text {fus }}(t)=y_{0}+\operatorname{TS} E Q \Phi_{\text {fus }}\left\{1+f_{\text {fus }}(t)\right\} \text {, }
$$

where $E Q$ is a weighting factor to allow for the higher degradation per unit fluence of the fusion neutrons as compared with fission neutrons :

For equal amount of permanent degradation

$$
\text { TS } \Phi_{\text {fiss }}=\text { TS } \Phi_{\text {fus }} \quad E Q
$$

the transient parts of equations (1) and (2) become:

$$
\begin{aligned}
& \hat{y}_{\text {fiss }}(t)=\Phi_{\text {fiss }} \hat{\mathrm{f}}_{\text {fiss }}(t) \\
& \hat{y}_{\text {fus }}(t)=\Phi_{\text {fus }} \text { EQ } \hat{\mathrm{f}}_{\text {fus }}(t)
\end{aligned}
$$


The constant TS has been incorporated into the functions.

In this analysis we have assumed that the decay function for fusion neutrons is not the same as that for fission neutrons. This is of very great practical importance. For example, suppose that, for equal amounts of permanent degradation, fusion neutrons give significantly more transient degradation than fission neutrons; then the electronic part of a weapon system, whose transient response is based on fission neutrons, would require a longer time to recover when exposed to fusion neutrons. This is even though both types of neutrons create the same permanent degradation.

One experimental method to determine if $f_{f i s s}(t)$ and $f_{f u s}(t)$, as defined by equations (4) and (5), are significantly different requires intense pulsed sources of fission and fusion neutrons. Fast burst reactors give intense $\mu s$ pulses of fission neutrons. The fluence is more than sufficient to degrade both narrow base high frequency bipolar transistors and JFETs. The only source of $14 \mathrm{MeV}$ neutrons sufficient for the complementary experiment is from a nuclear weapon. Unfortunately, the pulse repetition frequency for underground or full scale testing at the Nevada Test Site is quite long. Thus experimenters have devised less direct methods.

In 1968, Molander and Wikner [2] compared the relative effects of fission and fusion neutrons on short term annealing behavior by correlating existing experimental and theoretical information. They concluded that the damage produced in the two situations would probably not vary greatly in annealing characteristics. In 1971, Holmes, Wilson and Blair [3] presented experimental results 
which supported this viewpoint. These latter experimenters used typical high frequency transistors but performed their irradiation with the devices cooled. The devices were then quickly heated to observe the transient annealing. In this way the experimenters were able to use a neutron generator in the dc or steady state mode to irradiate the devices up to $10^{13} \mathrm{n} / \mathrm{cm}^{2}$ of $14 \mathrm{MeV}$ neutrons. Srour and Curtis [4], on the other hand, have used the available pulsed $14 \mathrm{MeV}$ neutron sources. Using a pulsed neutron generator at $10^{9} \mathrm{n} / \mathrm{cm}^{2}$ per pulse, they obtained fairly conclusive evidence that, as far as bulk silicon short term annealing is concerned, $14 \mathrm{MeV}$ neutrons create more annealable damage than do fission neutrons, for the same amount of permanent damage. With the advent of the dense-plasma-focus (D.P.F.) $14 \mathrm{MeV}$ neutron source $\left(1-5 \times 10^{10} \mathrm{n} / \mathrm{cm}^{2}\right.$ per pulse) srour and curtis have provided a definitive measurement of the difference, finding that, at 20 us after the pulse, the annealable damage at room temperature from fusion neutrons is 1.7 times that from fission neutrons, Eig. 2 .

$$
C / D=1.7
$$

The low $14 \mathrm{MeV}$ fluence forced srour and Curtis to use very neutron sensitive semiconductor parameters, such as the temporal behavior of the base minority carrier lifetime in solar cells, as measures of the transient recovery of neutron produced damage. They also selected low frequency, wide base, large transistors and monitored the temporal behavior of the common emitter current 


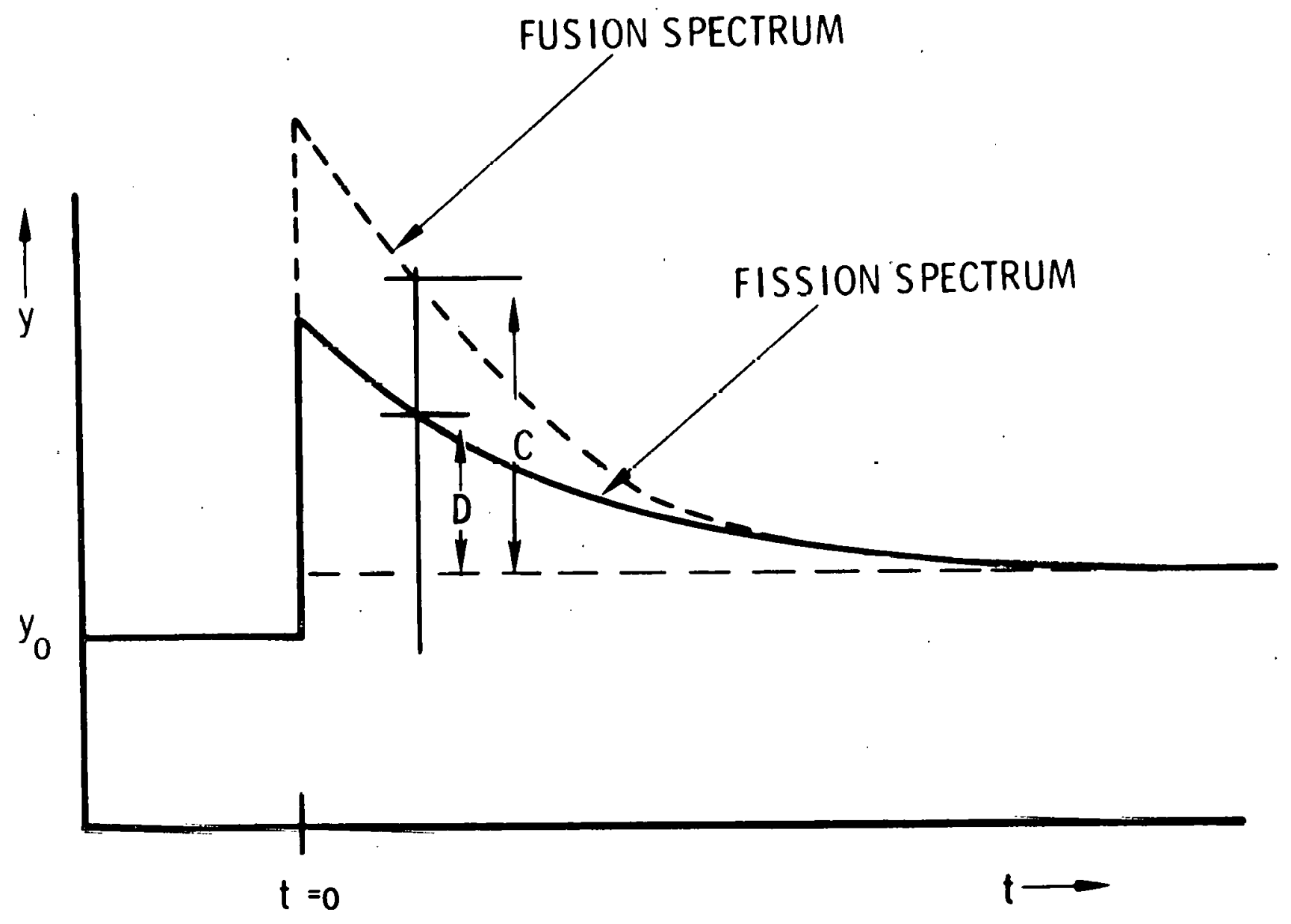

Figure 2. Transient Annealing Fission \& Fusion Neutrons (Srour \& Curtis). 
gain, $\beta$, after the neutron pulse. This raises the question of how relevant these measurements are to the temporal behavior, after a neutron pulse, of modern high frequency narrow base transistors and of JFETS.

\section{Proposed Experiments}

The proposed experiments will use typical neutron hard devices and the fluence levels will be appropriate for these types of devices. The rate of transient annealing is both temperature and injection current dependent. Thus, by cooling the devices and by using pulsed techniques for measurement, we can appreciably slow down the transient response.

There are two methods of performing experiments using the fast burst reactor fission spectrum. Fig. 3 demonstrates the first method. Each unit of a family of devices is mounted in a cryostat and held at low temperature. It is then subjected to a very short pulse (essentially a $\delta$ function) of fission neutrons and a measurement is made of the transient decay. The set of experimental points can be fitted with an analytical function, $f_{1}(t)$, to facilitate determination of an amplitude and a time decay to represent $f_{\text {fiss }}(t)$ of equation (4).

The second set of experiments involves another group of the same family of devices. Again the devices are cooled and pulsed techniques are used for the device characteristic measurements. However; this time the devices are subjected to prolonged steady state fission neutron irradiations as illustrated in Fig. 4. Measurements can start only after the irradiation is complete. 

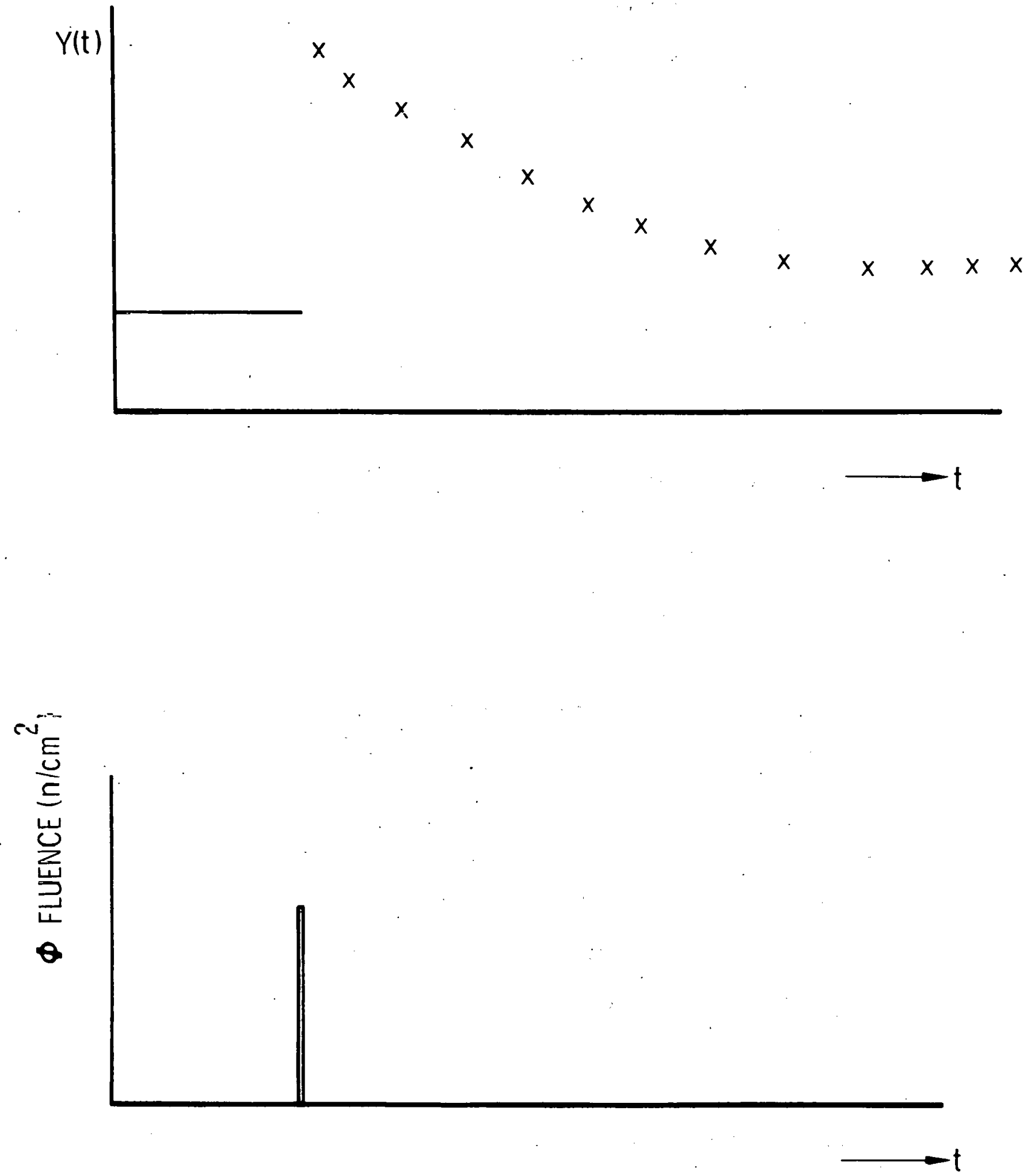

Figure 3. Transient Response after Exposure to $\delta$ Function of Neutrons. 

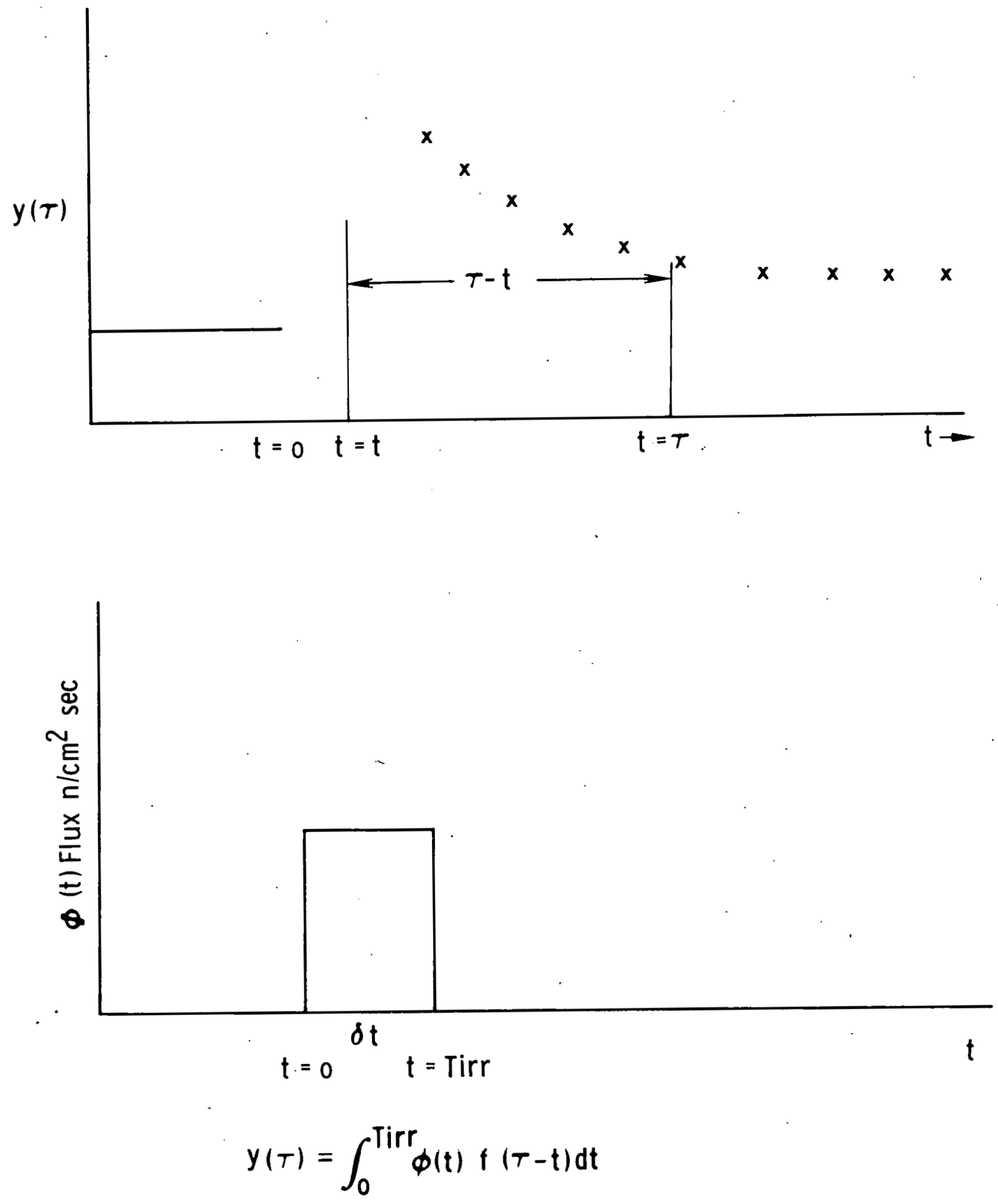

Figure 4. Transient Response after Exposure to DC Function of Neutrons. 
Consider a measurement of the parameter $y$ at time $\tau, y(\tau)$. This is made up of the sum over the irradiation time of the damage caused by the elements of fluence $\phi(t) \delta t$ decaying for a time $(\tau-t)$ or

$$
Y(\tau)=T S \int_{0}^{T_{i r r}} \phi(t) f(\tau-t) d t .
$$

We have a series of experimental measurements $y(\tau)$, we know $\phi(t)$ and thus hovc a ect of integral eguations ton unfold to get an estimate, $f_{2}(t)$, of $f(t)$. The analytical representation will enable us to obtain an amplitude and time decay term. Except for the variation from transistor to transistor these should be the same as from the previous experiment. That is, $f_{1}(t)$ from the first experiment should be the same as $f_{2}(t)$ from the second experiment except for experimental error and transistor to transistor variation.

The underlying assumption between the flrst two experiments is that there is no rate dependence of transient neutron degradation. This is not unreasonable since there is no rate dependence of permanent neutron degradation.

The third set of experiments involves exposing another group of the same family to devices to a $14 \mathrm{MeV}$ prolonged neutron irradiation. 'l'he $14 \mathrm{MeV}$ fluence should be adjugted eo achieve about the same permanent parameter degradation as the fission neutrons. Aqain the devices are cooled and pulsed techniques are used for their measurements.

The integral equation to be unfolded is similar to equation 8 except for a constant, EQ, and the necessary reduction of 
of the $14 \mathrm{MeV}$ fluence to obtain the same permanent degradation as the fission fluence,

or

$$
y(\tau)=\operatorname{TS} E Q \int_{0}^{T} \operatorname{irr} \phi(t) E(\tau-t) d t .
$$

The unfolding of this equation will yield an estimate expression $\mathrm{f}_{3}(\mathrm{t})$ for the decay function.

According to Srour and Curtis, $f_{3}(t)$ from the $3 r d$ experiment should be very different from $f_{I}(t)$ from the lst experiment and $f_{2}(t)$ from the second experiment: the latter two functions should be essentially the same. Molander, Wikner, Holmes, Wilson and Blair would say that all three are the same within the experimental error.

The three basic experiments just described should answer this question. However, to cover all possibilities, the three experiments should be performed with npn and pnp bipolar transistors and $\mathrm{p}$ and $\mathrm{n}$ channel JFETS.

\section{Prediction Analysis}

Prediction analysis is a technique that can be used to plan quantitative experiments. The technique offers savings of time, money, and energy for complicated, costly, and timeconsuming experiments. The method of prediction analysis essentially means performing the experiment but in a mathematical sense. Realistic values and errors are assigned to the variables and the data reduction performed. A determination 
is then made as to whether the experiments are capable of returning the desired result within the experimental tolerance.

For our particular case we are interested in the experiments resolving the question of the amplitude and time decay of the fission and fusion transient degiadationc. The initial magnitude of the fission neutron transient is approximately 4 times thc permanent degradation. Srour and Curtis measure the fusion case as 1.7 times the tission care. Thus we aim to differentiate a factor of 1.7 .

The envisaged experimental configuration is illustrated in Fig. 5. The transistor is mounted at the end of a cold copper finger which is cooled with liquid nitrogen. A heater is used to maintain the temperature at some intermediate point, probably about $-30 \mathrm{C}$. As the neutron sensitive parameter, we will use drain current on the 2 N4416 n channel JEET. A population of 2N4416's will not all have exactly the same value of unirradiated drain current, $I_{D S S}$. The population of drain currents is normally distributed, and may be represented by a mean and an associated standard deviation. Typical values for a population of 2N4416's are:

$$
\bar{I}_{D S S}=11 \mathrm{~mA}, \quad s=.3 \mathrm{~mA}
$$

Transistors, even from the same population, are not identical in their neutron permanent degradation sensitivity. There is also no correlation between parameters: the high gain transsistors of the population, on the average, degrade the same as 


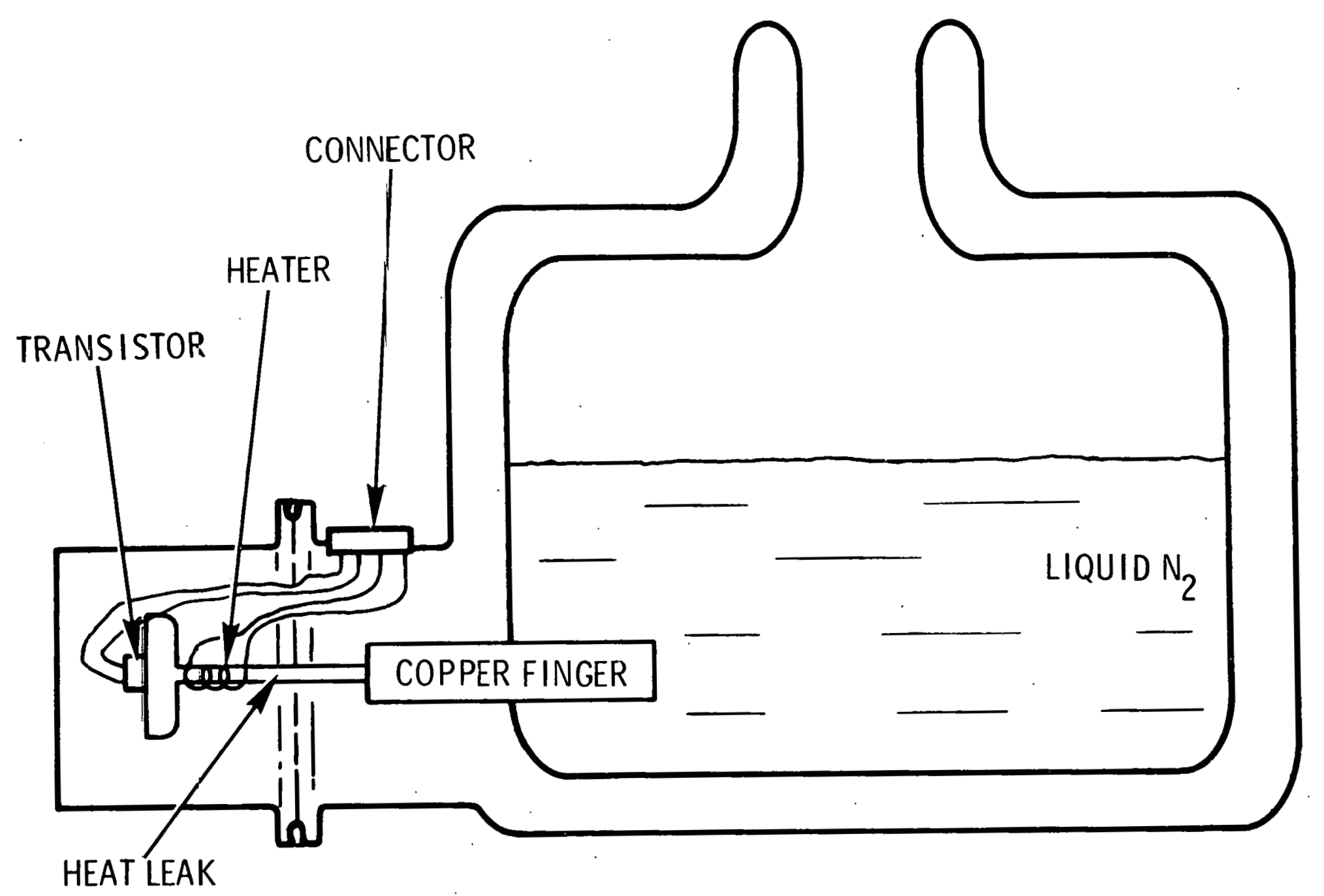

\section{LIQUID N $\mathrm{N}_{2}$ CRYOSTAT}

Figure 5. Experimental Configuration for Transient Annealing Experiments. 
the low gain transistors. The neutron degradation sensitivity of a population of $2 \mathrm{~N} 4416$ 's has a normal distribution with a mean value of about $-1 \mathrm{~mA}$ per $10^{14}$ Fast Burst Reactor $\mathrm{n} / \mathrm{cm}^{2}$ and an associated standard deviation of $.2 \mathrm{~mA}$.

If we aim to irradiate the transistors to $10^{14} \mathrm{n} / \mathrm{cm}^{2}$ we will achieve about this level. The actual level will be somewhere within a normal distribution of mean $1.0 \times 10^{1.4}$ FBR $\mathrm{n} / \mathrm{cm}^{2}$ and $\sigma=0.2 \times 10^{14} \mathrm{n} / \mathrm{cm}^{2}$.

Thus each transistor has to be assigned an initial drain current from a normal distribution of drain currents; the radiation degradation sensitivity is from another normal distribution; while the fluence which irradiates the transistor is from still another normal distribution.

The method of acsigning the actual values is to calculate a random normal number, $z_{\rho}$ of mean value $\mu=0$, and $\sigma=1$. The corresponding random normal number $x$, of mean $\bar{x}$, and standard deviation $\sigma$ is given by:

$$
x=z_{P} \sigma+\bar{x}
$$

The assignment for transistor \#1 is Unirradiated $1_{D S S}=11.24 \mathrm{~mA}$. Neutron sensitivity $\mathrm{TS}=-1.19 \mathrm{~mA} / 10^{14} \mathrm{FBR} \mathrm{n} / \mathrm{cm}^{2}$ Irradiation fluence $\Phi=0.83 \times 10^{14} \mathrm{FBR} \mathrm{n} / \mathrm{cm}^{2}$ Table I gives the assignment for 5 transistors. The transient response is 
Table 1. Assignments Made to 5 Transistors

\begin{tabular}{lccccc}
\hline Transistor \# & 1 & 2 & 3 & 4 & 5 \\
\hline$I_{\text {DSS }} \mathrm{mA}$ & 11.24 & 10.99 & 10.70 & 10.82 & 11.18 \\
$\phi \times 10^{-14} \mathrm{n} / \mathrm{cm}^{2}$ & .83 & 1.21 & 1.00 & 1.14 & .97 \\
TS $\mathrm{mA} / 10^{14} \mathrm{n} / \mathrm{cm}^{2}$ & 1.19 & 1.10 & 1.03 & .76 & 1.02 \\
AMP & 4.02 & 3.78 & 4.26 & 3.49 & 3.84 \\
TC & 94.4 & 98.3 & 97.6 & 103.9 & 96.6 \\
\hline
\end{tabular}




$$
\bar{Y}(t)=I_{D S S}-\text { TS } \Phi\{1+f(t)\}
$$

Arbitrarily we have made

$$
f(t)=\operatorname{AMP} e^{-t / T C}
$$

Experimentally AMP is approximately 4. However, it also probably varies from transistor to transistor; thus each transistor needs a random assignment for AMP. Similar arguments apply to TC. Thus both AMP and TC are assumed from normal distributions of mean values

and

$$
\begin{aligned}
& \overline{\mathrm{AMP}}=4.0, \quad \sigma=.4 ; \\
& \overline{\mathrm{TC}}=100, \quad \sigma=10 .
\end{aligned}
$$

The particular assignments made to transistor \#l are

$$
\begin{aligned}
\mathrm{AMP} & =4.02 ; \\
\mathrm{TC} & =94.4 .
\end{aligned}
$$

Thus for transistor \#l,

$$
y(t)=11.24-1.19 \times 0.83\left\{1-4.02 c^{-t / 94.4}\right\} .
$$

This is the true value of transient response but we make a measurement $y(t)$ of $\bar{y}(t)$. This meacurellint will have some error. The assumption is that $y(t)$ is normally distributed with mean $\bar{y}(t)$ and $\sigma=18$ of the mean. This error is applied as previously with random normal numbers. The measurement of the pre- and post-irradiation drain currents are assumed to be normally distributed with $\sigma=0.1 \%$ of the mean. These errors 
are also applied with random normal numbers. The temperature dependence of drain current is $-.05 \mathrm{~mA} / \mathrm{C}$. We believe we can maintain temperatures to within $0.1 \mathrm{C}$ at $-30 \mathrm{C}$ and thus consider the change of drain current with temperature as outside the experimental tolerances. Table 2 lists the results an experimenter could expect to get from 5 transistors. The fluence has been chosen so that the drain current does not saturate. From previous experiments we know that the permanent change in drain current is linear with fluence down to at least $2 \mathrm{~mA}$. Thus the transistors remain within their linear range. Having obtained results, the experimenter could choose to plot the results as illustrated in Fig. 6 . We have chosen to use a computer code, IUNFLD, and to represent $y(t)$ as a linear sum of quadratic B splines. The fit of the B splines to the data for transistor \#1 is given in Table 3. This program indicates how well the solution fits the data. Thus, in 1 ine 1 , only .385 of the tolerance is required for the fit. There is also a probability Chisquared which describes how well the solution fits the data. From the solution. Tahle 4, we are able to get the value

$$
\begin{aligned}
& y(t=0)=6.30, \quad s=.06 \\
& \text { Thus. AMP }= \frac{I_{D S S}(t+\infty)-y(t=0)}{I_{D S S}(t=0)-I_{D S S}(t+\infty)} \\
&= \frac{10.24-6.30}{11.26-10.24} \\
&= 3.86, s=.08
\end{aligned}
$$


Table.2. Simulated Measurements of 5 Transistors $\delta$ Function Irradiation

\begin{tabular}{lccccc} 
Trans. \# & 1 & 2 & 3 & 4 & 5 \\
$\begin{array}{l}\text { PIeldu } \\
\text { I }\end{array}$ & 11.26 & 10.99 & 10.69 & 10.83 & 11.19 \\
\hline
\end{tabular}

Time Secs. $\quad I_{D S S}(t) \mathrm{mA}$

\begin{tabular}{|c|c|c|c|c|c|c|}
\hline & $\begin{array}{r}1.00 \\
3.00 \\
6.00 \\
10.00 \\
15.00 \\
21.00 \\
28.00 \\
36.00 \\
45.00 \\
55.00 \\
66.00 \\
78.00 \\
91.00 \\
105.00 \\
120.00 \\
136.00 \\
153.00 \\
171.00 \\
190.00 \\
210.00 \\
231.00 \\
253.00 \\
276.00 \\
300.00 \\
325.00 \\
351.00 \\
378.00 \\
406.00 \\
435.00 \\
465.00\end{array}$ & $\begin{array}{l}6.30 \\
6.44 \\
6.59 \\
6.75 \\
6.89 \\
7.04 \\
7.31 \\
7.53 \\
7.91 \\
8.03 \\
8.37 \\
8.74 \\
9.66 \\
8.99 \\
9.12 \\
9.22 \\
9.25 \\
9.62 \\
9.72 \\
9.67 \\
9.68 \\
9.97 \\
0.23 \\
10.07 \\
10.03 \\
0.04 \\
10.15 \\
10.29 \\
0.26 \\
0.26\end{array}$ & $\begin{array}{l}4.65 \\
4.84 \\
4.94 \\
5.07 \\
5.30 \\
5.59 \\
5.97 \\
6.15 \\
6.49 \\
6.65 \\
7.02 \\
7.37 \\
7.70 \\
7.83 \\
8.20 \\
8.35 \\
8.64 \\
8.82 \\
8.88 \\
9.01 \\
9.20 \\
9.39 \\
9.48 \\
9.52 \\
9.46 \\
9.46 \\
9.64 \\
9.53 \\
9.65 \\
9.57\end{array}$ & $\begin{array}{l}5.42 \\
5.36 \\
5.60 \\
5.70 \\
5.86 \\
6.24 \\
6.44 \\
6.70 \\
6.97 \\
7.21 \\
7.48 \\
7.62 \\
7.98 \\
8.32 \\
8.42 \\
8.59 \\
8.57 \\
8.82 \\
9.05 \\
9.22 \\
9.20 \\
9.42 \\
9.34 \\
9.48 \\
9.47 \\
9.47 \\
9.67 \\
9.53 \\
9.64 \\
9.55\end{array}$ & $\begin{array}{r}6.87 \\
6.97 \\
7.15 \\
7.26 \\
7.25 \\
7.39 \\
7.77 \\
7.90 \\
7.95 \\
8.11 \\
8.38 \\
8.47 \\
8.88 \\
8.91 \\
8.92 \\
9.05 \\
9.16 \\
9.26 \\
9.54 \\
9.47 \\
9.51 \\
9.64 \\
9.93 \\
9.75 \\
9.67 \\
9.85 \\
10.06 \\
9.99 \\
9.79 \\
10.01\end{array}$ & $\begin{array}{r}6.44 \\
6.47 \\
6.73 \\
6.66 \\
6.95 \\
7.13 \\
7.45 \\
7.54 \\
7.75 \\
8.09 \\
8.36 \\
8.46 \\
8.66 \\
8.90 \\
9.11 \\
9.32 \\
9.46 \\
9.45 \\
9.66 \\
9.85 \\
9.71 \\
9.99 \\
9.93 \\
9.99 \\
10.12 \\
10.10 \\
10.10 \\
9.98 \\
10.16 \\
10.13\end{array}$ \\
\hline & $\begin{array}{l}\text { st } r \text { ad } \\
I_{\text {DSS }} m A\end{array}$ & 0.24 & 9.63 & 9.70 & 9.96 & 10.20 \\
\hline$\phi$ & $\times 10^{-14} \mathrm{n} / \mathrm{cm}^{2}$ & .85 & 1.20 & 1.01 & 1.16 & .98 \\
\hline
\end{tabular}




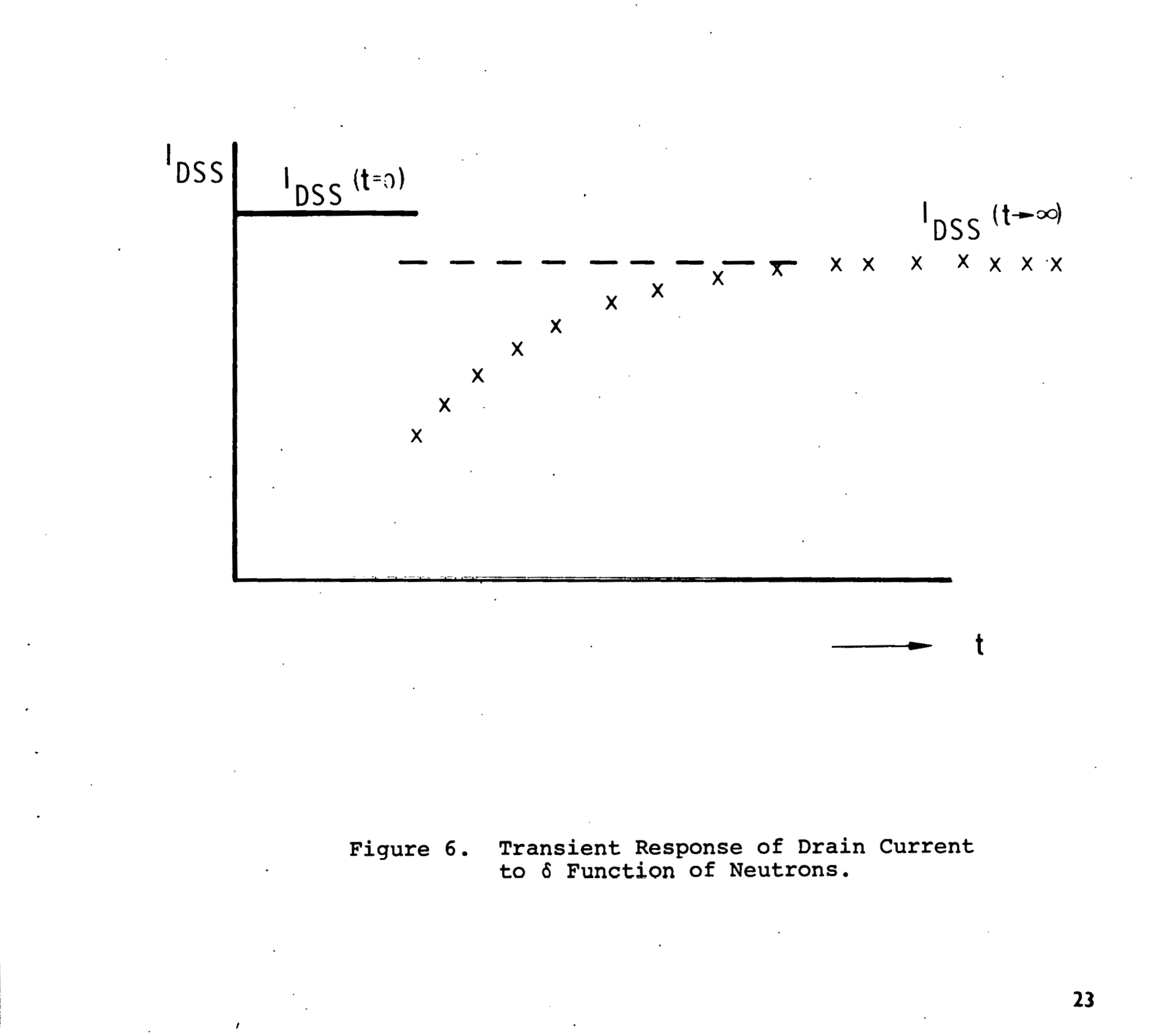


Table 3. Statistics of Quadratic B Spline Fit to the Simulated Experimental Data for \#l Transistor $\delta$ Function Case

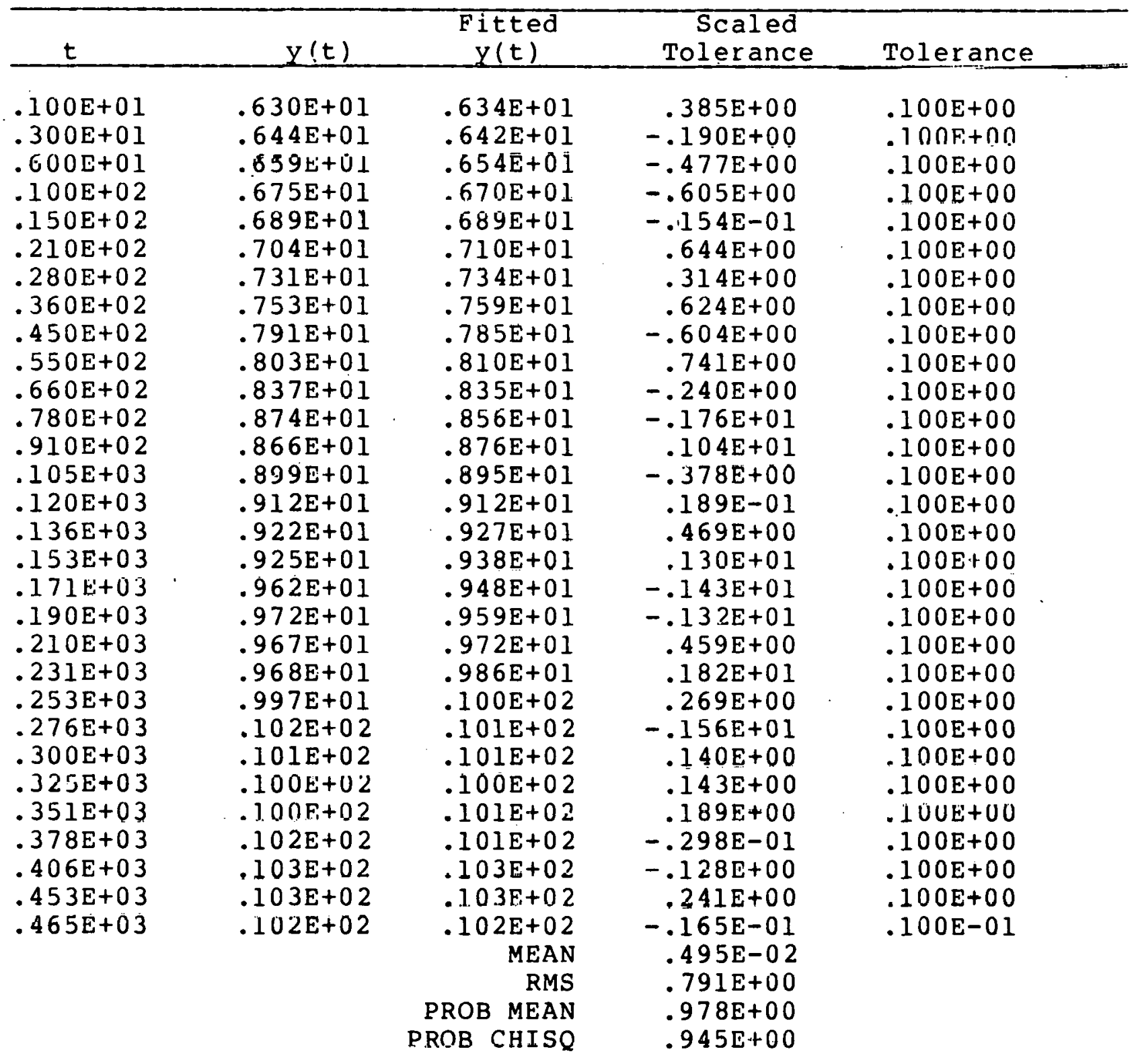


Table 4. Solution Data $y(t)$ of Quadratic B Spline Fit to the Simulated Experimental Data for \#l Transistor

$t$

0 .

$.186 \mathrm{E}+02$

$.372 \mathrm{E}+02$

$.558 \mathrm{E}+02$

$.744 \mathrm{E}+02$

$.930 \mathrm{E}+02$

$.112 \mathrm{E}+03$

$.130 \mathrm{E}+03$

$.149 \mathrm{E}+03$

$.167 \mathrm{E}+03$

$.186 \mathrm{E}+03$

$.205 \mathrm{E}+03$

$.233 \mathrm{E}+03$

$.242 \mathrm{E}+03$

$.260 \mathrm{E}+03$

$.279 E+03$

$.298 \mathrm{E}+03$

$.316 \mathrm{E}+03$

$.335 \mathrm{E}+03$

$.353 \mathrm{E}+03$

$.372 \mathrm{E}+0.3$

$.391 \mathrm{E}+03$

$.409 \mathrm{E}+03$

$.428 \mathrm{E}+03$

$.446 \mathrm{E}=03$

$.465 \mathrm{E}+03$ $y(t)$

$.62967 \mathrm{E}+01$

$.70195 \mathrm{E}+01$

$.76282 \mathrm{E}+01$

$.81230 \mathrm{E}+01$

$.85039 E+01$

$.87930 \mathrm{E}+01$

$.99309 E+01$

$.92186 \mathrm{E}+01$

$.93561 \mathrm{E}+01$

$.94567 \mathrm{E}+01$

$.95636 \mathrm{E}+01$

$.96802 \mathrm{E}+01$

$.98064 \mathrm{E}+01$

$.99357 \mathrm{E}+01$

$.10029 \mathrm{E}+02$

$.10079 \mathrm{E}+02$

$.10086 \mathrm{E}+02$

$.10055 \mathrm{E}+02$

$.10042 \mathrm{E}+02$

$.10064 \mathrm{E}+02$

$.10121 \mathrm{E}+02$

$.10212 \mathrm{E}+02$

$.10287 \mathrm{E}+02$

$.10316 \mathrm{E}+02$

$.10300 E+02$

$.10240 \mathrm{E}+02$
Std. Dev.

$.560 \mathrm{E}-01$

. $325 \mathrm{E}=01$

$.406 \mathrm{E}-01$

$.439 \mathrm{E}-01$

$.381 \mathrm{E}-01$

$.423 \mathrm{E}-01$

$.491 \mathrm{E}-01$

$.479 \mathrm{E}-01$

$.420 \mathrm{E}-01$

$.471 \mathrm{E}-01$

$.546 \mathrm{E}-01$

$.538 \mathrm{E}-01$

$.470 \mathrm{E}-01$

$.501 \mathrm{E}-01$

$.590 \mathrm{E}-01$

$.593 \mathrm{E}-01$

. $521 \mathrm{E}-01$

$.537 \mathrm{E}-01$

$.641 \mathrm{E}-01$

$.646 \mathrm{E}-01$

$.573 \mathrm{E}-01$

$.658 \mathrm{E}-01$

$.858 \mathrm{E}-0 \mathrm{l}$

$.848 \mathrm{E}-01$

$.568 \mathrm{E}-01$

$.998 \mathrm{E}-02$

$$
y^{\prime}(t)
$$

$y^{\prime \prime}(t)$

$.419 \mathrm{E}-01$

$-.329 \mathrm{E}-03$

$.358 \mathrm{E}-01$

$.297 \mathrm{E}-01$

$.235 E-01$

$.174 \mathrm{E}-01$

. $141 \mathrm{E}-01$

. $114 \mathrm{E}-01$

$.874 \mathrm{E}-02$

$.604 \mathrm{E}-02$

$.549 \mathrm{E}-02$

$.601 E-02$

$.653 E-02$

$.705 \mathrm{E}-02$

$.615 \mathrm{E}-02$

$.385 \mathrm{E}-02$

$.155 \mathrm{E}-02$

$-.759 \mathrm{E}-03$

-.1663-02

$.234 \mathrm{E}-03$

$.213 E-02$

$.403 \mathrm{E}-02$

$.520 \mathrm{E}-02$

$.279 E-02$

$.368 E-03$

$-.205 \mathrm{E}-02$

$-.447 \mathrm{E}-02$

$-.329 \mathrm{E}-03$

$-.329 \mathrm{E}-03$

$-.329 \mathrm{E}-03$

$-.329 \mathrm{E}-03$

-.145E-03

$-.145 \mathrm{E}-03$

$-.145 \mathrm{E}-03$

$-.145 E-03$

$.279 E-04$

$.279 E-04$

$.279 E-04$

$.279 \mathrm{E}-04$

$-.124 \mathrm{E}-03$

$-.124 \mathrm{E}-03$

$-.124 \mathrm{E}-03$

$-.124 \mathrm{E}-03$

$.102 \mathrm{E}-03$

$.102 \mathrm{E}-03$

$.102 \mathrm{E}-03$

$.102 \mathrm{E}-03$

$-.130 \mathrm{E}-03$

$-.130 \mathrm{E}-03$

-.130E-03

$-.130 \mathrm{E}-03$

$-.130 \mathrm{E}-03$ 
The amplitudes at $t=0$, and the time taken for the amplitudes to decay to $1 / 2$ are 1 isted in Table 5, for the 5 transistors. Also 1 isted are the individual input amplitudes and their associated time to $1 / 2$ amplitude values. An examination of these data reveals that this experiment, as it is postulated, can measure the transistor to transistor variation. The measurement errors are relatively smal1. Thus, the standard deviation of the solutions are the same as the standard deviations of input data considering the small sample size.

For the second experiment the device parameters and ir radiations are chosen also from a random normal distribution. To facilitate the development of the integral equation we have included the $14 \mathrm{MeV}$ equivalence parameter in the expression. We will, therefore, merely alter the amplitude of the decay function to simulate the possible difference for $14 \mathrm{MeV}$ neutron irradiations. The device parameters are:

$$
I_{D S S} \text { pre-rad }=11 \mathrm{~mA}, \sigma=0.3
$$

Transistor neutron sensitivity $\mathrm{TS}=1.0 \mathrm{~mA} / 10^{1.4}$

$$
\text { equivalent } F B R \mathrm{n} / \mathrm{cm}^{2}, \sigma=0.2
$$

Equivalent degradation per unit fluencc of fusion relative to fission neutrons $E Q=3.0, \sigma=0.1$

Flux $\phi(t)$ constant during $\mathrm{T}_{\text {irr }}=.0111 \times 10^{14} \mathrm{n} / \mathrm{cm}^{2} \mathrm{~s}, \sigma=.0005$

$$
\text { Irradiation Time } \mathrm{T}_{\text {irr }} \neq 30 \mathrm{~s}
$$


Table 5. Input Data and Solution Comparison for $\delta$ Function Irradiation

\begin{tabular}{|c|c|c|c|c|}
\hline Trans.\# & $\begin{array}{c}\text { Solution } \\
f(t=0)\end{array}$ & $\begin{array}{l}\text { Input } \\
\text { Amp }\end{array}$ & $\begin{array}{l}\text { Solution } \\
t(1 / 2 \text { Amp })\end{array}$ & $\begin{array}{c}\text { Input } \\
t(1 / 2 \text { Amp })\end{array}$ \\
\hline 1 & 3.86 & 4.02 & 62.2 & 65.4 \\
\hline 2 & 3.65 & 3.78 & 69.0 & 68.1 \\
\hline 3 & 4.25 & 4.26 & 66.6 & 67.7 \\
\hline 4 & 3.52 & 3.49 & 69.8 & 72.0 \\
\hline 5 & 3.83 & 3.84 & 66.5 & 67.0 \\
\hline Means & 3.8 & 3.9 & 67 & 68 \\
\hline Std. Dev. & .3 & .3 & 3 & 3 \\
\hline
\end{tabular}


The transient waveforms are shown in Fig. 7. The permanent drain current change due to the element of Eluence $\phi(t) \delta t$

$$
=\phi(t) \delta t \text { TS EQ }
$$

The transient change at time $\tau$ due to this element

$$
=\phi(t) \delta t \operatorname{TS} E Q f(\tau-t)
$$

The transient change at time $\tau$ considering all the irradiation

$$
y(\tau)=\operatorname{TSEQ} \int_{0}^{T_{i r r}} \phi(t) f(\tau-t) d t
$$

As in the first experiment we will make the transient function. an exponential or

$$
E(\tau-t)=A M P e^{-(\tau-t) / T C}
$$

where

$$
\overline{\mathrm{AMP}}=4, \sigma=.4
$$

and

$$
\overline{\mathrm{TC}}=100, \sigma=10
$$

The drain curent at time $\tau$ is equal to the degraded drain current minus the transient change.

$$
\begin{aligned}
I_{D S S}(\tau)= & I_{D S S}(t \rightarrow \infty)-y(\tau) \\
= & \left\{I_{D S S}(t=0)-\overline{T S} \phi E\left({ }^{\prime} I_{i r r}\right\}\right. \\
& -y(\tau),
\end{aligned}
$$

and $\phi$ is assumed constant during the irradiation.

A measurement is made of this drain current. Thus we have added a normally distributed error of 0.28 of the mean. Further 


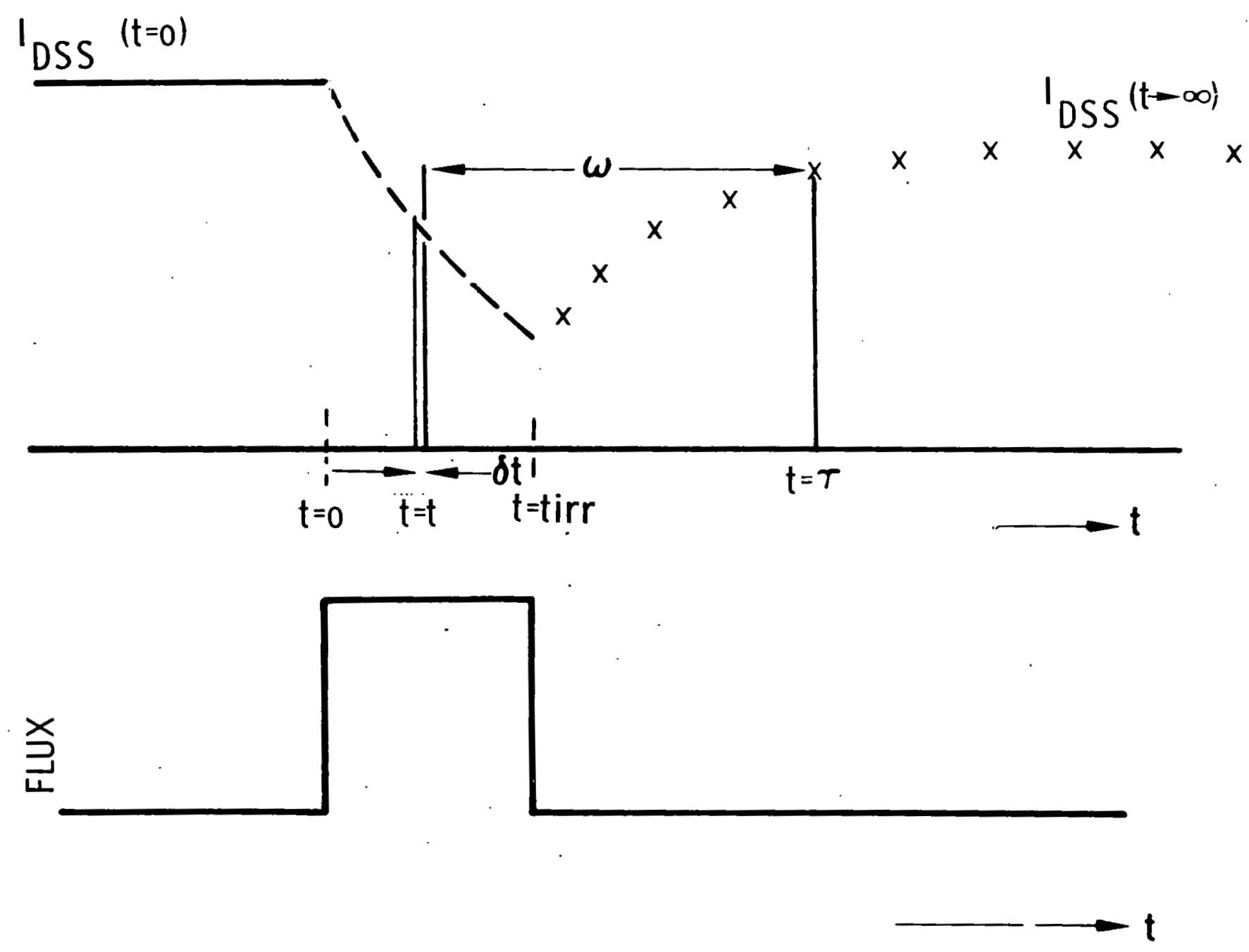

Figure 7. Transient Response Following Square Wave Irradiation. 
we have assumed that we can measure the initial and final value of drain currents with a $0.1 \%$ error. All values for 5 transistors are 1 isted in Table 6 .

It is from the measured values that we have to obtain the transient response. The measured transient response $\hat{y}(\tau)$ is equal to the difference between the measured permanently degraded drain current, $\hat{I}_{\text {DSS }}(t \rightarrow \infty)$, and measured value of arain current at Lime $t=\tau, I_{\text {DSS }}(\tau)$

$$
\text { or } \begin{aligned}
\hat{y}(\tau) & =I_{D S S}(t \rightarrow \infty)-I_{D S S}(\tau) \\
\text { and } \hat{y}(\tau) & =\int_{0}^{T}{ }^{T} \phi(t) f(\tau-t) d t
\end{aligned}
$$

where $f(\tau-t)$ is the function to be estimated. Equation (10) is not in the correct form for the unfolding code. IUNFLD solves the integral equalions

$$
G(x)=\int_{E_{1}}^{E_{2}} R(t, x) E(t) d t,
$$

where $f(t)$ is the unknown function to be estimated, $R(t, x)$ is the forcing function, and $G(x)$ is known with approximate tolerances $\varepsilon_{i}$ at $x_{i}, i=1, N u$ where $N u$ is the number of experimental points. We can change equation (10) into the correct format by making the substitution

$$
\begin{aligned}
\tau-t & =\omega \\
-d t & =d \omega .
\end{aligned}
$$

Equation (10) thus becomes

$$
\hat{y}(\tau)=\int_{\max \left(\tau-T_{i r r}, 0\right)}^{\tau} \phi(\tau-\omega) E(\omega) d \omega .
$$


Table 6. Simulated Measurements of 5 Transistors, Long Irradiation

\begin{tabular}{|c|c|c|c|c|c|}
\hline Trans \# & 1 & 2 & 3 & 4 & 5 \\
\hline $\mathrm{TS} \mathrm{mA} / 10^{14} \mathrm{n} / \mathrm{cm}^{2}$ & .92 & 1.03 & .98 & 1.33 & .99 \\
\hline $\mathrm{EQ}$ & 2.89 & 2.97 & 3.09 & 3.05 & 3.04 \\
\hline$I_{D S S}$ & 10.91 & 11.14 & 11.29 & 11.3 & 11.12 \\
\hline $\mathrm{Flux} \mathrm{n} / \mathrm{cm}^{2} \mathrm{~s} \times 10^{-14}$ & .01 & .01 & .01 & .01 & .01 \\
\hline AMP calculated & 3.60 & 3.07 & 4.05 & 4.0 & 3.39 \\
\hline TC calculated & 76.98 & 99.20 & 118.77 & 98.0 & 90.80 \\
\hline$I_{D S S}(t=0)$ measured & 10.90 & 11.14 & 11.30 & 11.3 & 11.12 \\
\hline Time $\mathrm{S}$ & & $\bar{I}_{D S S}$ & $\mathrm{~mA}$ & & \\
\hline $\begin{array}{l}31.00 \\
33.00 \\
36.00 \\
40.00 \\
45.00 \\
51.00 \\
58.00 \\
66.00 \\
75.00 \\
85.00 \\
96.00 \\
108.00 \\
121.00 \\
135.00 \\
150.00 \\
166.00 \\
183.00 \\
201.00 \\
220.00 \\
240.00 \\
261.00 \\
283.00 \\
306.00 \\
330.00 \\
355.00 \\
381.00 \\
408.00 \\
436.00 \\
465.00 \\
495.00\end{array}$ & $\begin{array}{r}7.26 \\
7.33 \\
7.44 \\
7.59 \\
7.71 \\
7.98 \\
8.04 \\
8.24 \\
8.45 \\
8.65 \\
8.80 \\
8.99 \\
9.13 \\
9.29 \\
9.41 \\
9.50 \\
9.60 \\
9.69 \\
9.77 \\
9.83 \\
9.87 \\
9.88 \\
9.90 \\
9.95 \\
9.98 \\
9.97 \\
9.95 \\
10.01 \\
9.95 \\
10.00\end{array}$ & $\begin{array}{l}7.05 \\
7.11 \\
7.20 \\
7.30 \\
7.44 \\
7.56 \\
7.75 \\
7.95 \\
8.11 \\
8.28 \\
8.45 \\
8.62 \\
8.81 \\
8.98 \\
9.10 \\
9.26 \\
9.35 \\
9.47 \\
9.56 \\
9.63 \\
9.73 \\
9.76 \\
9.82 \\
9.84 \\
9.87 \\
9.91 \\
9.95 \\
9.97 \\
9.94 \\
9.95\end{array}$ & $\begin{array}{l}6.85 \\
6.92 \\
6.99 \\
7.13 \\
7.25 \\
7.38 \\
7.55 \\
7.72 \\
7.91 \\
8.13 \\
8.30 \\
8.49 \\
8.69 \\
8.91 \\
9.04 \\
9.18 \\
9.35 \\
9.52 \\
9.63 \\
9.69 \\
9.83 \\
9.90 \\
9.96 \\
10.07 \\
10.06 \\
10.14 \\
10.17 \\
10.23 \\
10.21 \\
10.23\end{array}$ & $\begin{array}{l}5.26 \\
5.36 \\
5.50 \\
5.68 \\
5.90 \\
6.12 \\
6.39 \\
6.68 \\
6.94 \\
7.26 \\
7.53 \\
7.81 \\
8.09 \\
8.33 . \\
8.56 \\
8.74 \\
8.96 \\
9.12 \\
9.26 \\
9.41 \\
9.50 \\
9.62 \\
9.66 \\
9.76 \\
9.76 \\
9.84 \\
9.84 \\
9.88 \\
9.87 \\
9.94\end{array}$ & $\begin{array}{l}7.31 \\
7.37 \\
7.48 \\
7.57 \\
7.72 \\
7.86 \\
8.03 \\
8.20 \\
8.38 \\
8.56 \\
8.76 \\
8.95 \\
9.08 \\
9.22 \\
9.35 \\
9.47 \\
9.58 \\
9.68 \\
9.75 \\
9.87 \\
9.91 \\
9.94 \\
10.00 \\
10.07 \\
10.06 \\
10.07 \\
10.05 \\
10.12 \\
10.08 \\
10.10\end{array}$ \\
\hline I Dss $(t \rightarrow o f$ measured & 10.00 & 10.00 & 10.32 & 9.96 & 10.13 \\
\hline Fluence $\times 10^{-14} \mathrm{n} / \mathrm{cm}^{2}$ & .35 & .37 & .32 & .34 & .33 \\
\hline
\end{tabular}


and we are able to solve the set of equations to estimate $f(\omega)$. In the solution we simulated the flux with a unit function of appropriate length. Thus $f(\omega)$ contains the magnitude of the flux and by comparison with equation (9) also the values TS and EQ. Thus $\hat{f}(\omega)$ to be compared with $f(t)$ from the first experiment is given by

$$
\hat{t}(\omega)=\frac{E(\omega)}{\operatorname{TS} E Q \phi}
$$

The permanent change in drain current, which ot course is a measurable quantity is given by

$$
\Delta I=I^{\prime} S \mathrm{EQ} \phi \mathrm{T}_{\text {irr }}
$$

Thus in terms of measurable guantities

$$
\hat{f}(\omega)=\frac{\mathrm{f}(\omega)}{\Delta I} \mathrm{~T}_{\text {irr }}
$$

Table 7 gives the input data to IUNFLD and the statistics of the solution. Table 8 gives the estimate for $f(u)$. The first thing that is apparent is that the solution at zero time has considerable error. Thus for comparison purposes of the decay to half amplitude, we need to advance in time from the 0 time position. We have taken the starting point as $t=20$. Results ful Lhe 5 trangiators are given in Table 9.

Examination of these data shows that the integral technique is capable of measurements which are essential as good as those from the $\delta$ function irradiations of the first experiment. The individual transistors were given amplitudes and time constants from normal distributions with standard 
Table 7. Statistics of a Quadratic B Spline Fit to Integral Equations for \#l Transistor dc Case

$\tau$

$.310 \mathrm{E}+02$

$.330 \mathrm{E}+02$

$.360 \mathrm{E}+02$

$.400 \mathrm{E}+02$

$.450 \mathrm{E}+02$

$.510 \mathrm{E}+02$

$.580 \mathrm{E}+02$

$.660 \mathrm{E}+02$

$.750 \mathrm{E}+02$

$.850 \mathrm{E}+02$

$.960 E+02$

$.108 \mathrm{E}+03$

$.121 \mathrm{E}+03$

$.135 E+03$

$.150 \mathrm{E}+03$

$.166 \mathrm{E}+03$

$.183 \mathrm{E}+03$

$.201 \mathrm{E}+03$

$.220 \mathrm{E}+03$

$.240 E+03$

$.261 \mathrm{E}+03$

$.283 E+03$

$.306 \mathrm{E}+03$

$.330 \mathrm{E}+03$

$.355 E+03$

$.381 \mathrm{E}+03$

$.408 E+03$

$.480 \mathrm{E}+03$ $y(\tau)$

$.274 \mathrm{E}+01$

$.267 \mathrm{E}+01$

$.256 \mathrm{E}+01$

. $241 \mathrm{E}+01$

$.229 E+01$

. 211E+01

$.196 \mathrm{E}+01$

$.176 \mathrm{E}+0 \mathrm{I}$

$.155 \mathrm{E}+01$

$.135 \mathrm{E}+01$

$.120 \mathrm{E}+01$

$.101 \mathrm{E}+01$

$.870 \mathrm{E}+00$

$.710 \mathrm{E}+00$

$.590 E+00$

$.500 \mathrm{E}+00$

$.400 \mathrm{E}+00$

. 310E+00

$.230 \mathrm{E}+00$

$.170 \mathrm{E}+00$

$.130 \mathrm{E}+00$

$.120 \mathrm{E}+00$

$.100 \mathrm{E}+00$

$.500 \mathrm{E}-01$

$.700 \mathrm{E}-01$

$.300 \mathrm{E}-01$

$.500 \mathrm{E}-01$

0 .

\section{Calculated} Integral

$.274 \mathrm{E}+01$ $.266 \mathrm{E}+01$

$.255 \mathrm{E}+01$

$.243 \mathrm{E}+01$

$.228 \mathrm{E}+01$

$.212 \mathrm{E}+01$

$.194 \mathrm{E}+01$

$.175 \mathrm{E}+01$

$.156 \mathrm{E}+01$

$.137 \mathrm{E}+01$

$.118 \mathrm{E}+01$

$.101 \mathrm{E}+01$

$.860 \mathrm{E}+00$

$.719 \mathrm{E}+00$

$.596 \mathrm{E}+00$

$.491 \mathrm{E}+00$

$.396 \mathrm{E}+00$

. $311 \mathrm{E}+00$

$.237 \mathrm{E}+00$

$.178 \mathrm{E}+00$

$.136 \mathrm{E}+00$

$.108 \mathrm{E}+00$

$.861 \mathrm{E}-01$

$.677 \mathrm{E}-01$

$.527 \mathrm{E}-01$

$.406 \mathrm{E}-01$

0 .

. 310E-01

MEAN

RMS

PROB MEAN

PROB CHISQ
Scaled

Tolerance

$.218 \mathrm{E}+00$

$-.409 \mathrm{E}+00$

$-.297 \mathrm{E}+00$

$.945 \mathrm{E}+00$

$-.321 \mathrm{E}+00$

$.481 \mathrm{E}+00$

$-.934 \mathrm{E}+00$

$.359 \mathrm{E}+00$

$.468 \mathrm{E}+00$

$.875 E+00$

$-.779 E+00$

$.248 \mathrm{E}+00$

$-.504 E+00$

$.446 \mathrm{E}+00$

$.310 \mathrm{E}+00$

$-.464 \mathrm{E}+00$

$-.201 \mathrm{E}+00$

$.257 \mathrm{E}-01$

$.348 \mathrm{E}+00$

$.400 \mathrm{E}+00$

$.311 \mathrm{E}+00$

$-.585 \mathrm{E}+00$

$-.697 \mathrm{E}+00$

$.885 \mathrm{E}+00$

$-.864 \mathrm{E}+00$

$.532 E+00$

$-.948 E+00$

0 .

$-.310 E-01$

$.564 \mathrm{E}+00$

$.870 \mathrm{E}+00$

$.100 \mathrm{E}+01$
Tolerance

$.200 E-01$

$.200 E-0 I$

.200E-0I

$.200 E-01$

.200E-01

$.200 E-01$

$.200 E-01$

. 200E-0I

$.200 E-01$

.200E-0I

$.200 E-01$

$.200 \mathrm{E}-01$

.200E-01

.200E-01

.200E-01

$.200 E-01$

$.200 \mathrm{E}-01$

$.200 \mathrm{E}-01$

.200E-01

. 200E-01

$.200 \mathrm{E}-01$

. 200E-01

$.200 \mathrm{E}-01$

$.200 \mathrm{E}-01$

$.200 \mathrm{E}-01$

. 200E-01

$.200 \mathrm{E}-01$

$.200 E-01$ 
Table 8. Estimate for $f(\omega)$ From Quadratic $B$ Spline Solutioin of Integral Data
$\omega$
$f(\omega)$
$\Delta \mathbf{f}(\omega)$
$E^{\prime}(\omega)$
$f^{\prime}(\omega)$

0 .

$.100 \mathrm{E}+02$

$.12234 \mathrm{E}+00$

$.151 \mathrm{E}-01$

$-.395 E-02$

$.276 \mathrm{E}-03$

$.96790 \mathrm{E}-01$

$.220 E-02$

$-.118 \mathrm{E}-02$

$.130 E-04$

$.200 \mathrm{E}+02$

$.439 E-03$

$-.105 \mathrm{E}-02$

$.130 E-04$

$.75724 \mathrm{E}-01$

$.603 E-03$

$-.923 \mathrm{E}-03$

$.811 \mathrm{E}-05$

$.400 \mathrm{E}+\mathrm{U} 2$

$.66897 \mathrm{E}-01$

$.350 E-03$

$-.842 \mathrm{E}-03$

$.811 E-05$

$.500 \mathrm{E}+02$

$.600 \mathrm{E}+02$

$.700 \mathrm{E}+02$

. $58880 \mathrm{E}-01$

$.303 E-03$

$-.761 \mathrm{E}-03$

$.811 E-05$

- $31674 \mathrm{E}-01$

$.359 E-03$

$-.680 \mathrm{E}-03$

$.811 \mathrm{E}-05$

$.39695 \mathrm{E}-01$

$-.599 E-03$

$.811 \mathrm{E}-05$

$.355 \mathrm{E}-03$

$.900 E+02$

$.34922 \mathrm{E}-01$

$.30774 \mathrm{E}-01$

$-.518 \mathrm{E}-03$

$.811 E-05$

$.304 \mathrm{E}-03$

$-.437 \mathrm{E}-03$

$.440 \mathrm{E}-05$

$.332 E-03$

$-.393 E-03$

$.440 E-05$

$.27066 \mathrm{E}-01$

$.384 \mathrm{E}-03$

$.23799 \mathrm{E}-01$

$.400 \mathrm{E}-03$

$.20972 \mathrm{E}-0 \mathrm{I}$

$.371 E-03$

$-.349 \mathrm{E}-03$

$.440 \mathrm{E}-05$

$.120 \mathrm{E}+03$

$.130 \mathrm{E}+03$

$.140 \mathrm{E}+003$

$.150 \mathrm{E}+03$

$.160 \mathrm{E}+03$

$.170 \mathrm{E}+03$

$.180 \mathrm{E}+03$

$.190 \mathrm{E}+03$

$.200 \mathrm{E}+03$

$.210 \mathrm{E}+03$

$.220 \mathrm{E}+03$

$.230 F+03$

$.240 \mathrm{E}+03$

$.250 \mathrm{E}+03$

$.260 \mathrm{E}+03$

$.270 \mathrm{E}+03$

$.28 \mathrm{UE}+03$

$.290 \mathrm{E}+03$

$.18586 \mathrm{E}-01$

$.319 E-03$

$.16499 \mathrm{E}-01$

$.14569 \mathrm{E}-01$

$.315 E-03$

$.349 \mathrm{E}-03$

$.12798 \mathrm{E}-01$

$.11184 \mathrm{E}-01$

$.97278 \mathrm{E}-02$

$.84296 \mathrm{t}-02$

$.72891 \mathrm{E}=02$

$.63064 \mathrm{E}-02$

$.54816 \mathrm{~F}-02$

$.48145 \mathrm{E}-02$

$.43061 \mathrm{E}-02$

$.38964 \mathrm{E}-02$

$.35256 \mathrm{E}-02$

. $31901 \mathrm{E}-02$

$.28865 \mathrm{E}-02$

$.300 \mathrm{E}+03$

$.26118 \mathrm{E}-02$

$.381 \mathrm{E}-03$

$.383 E-03$

$.383 \mathrm{E}-03$

$.361 \mathrm{k}-03$

$.352 \mathrm{E}=03$

$.399 \mathrm{E}-03$

$.526 \mathrm{E}-03$

$.727 E-03$

$.496 \mathrm{E}-03$

$.449 \mathrm{E}-03$

$.406 \mathrm{E}-03$

$.367 \mathrm{E}-03$

$.332 \mathrm{E}-03$

$.301 \mathrm{E}-03$

$-.305 \mathrm{E}-03$

$.440 \mathrm{E}-05$

$.440 \mathrm{E}-05$

$.158 \mathrm{E}-05$

$.158 \mathrm{E}-05$

$.158 \mathrm{E}-05$

$.158 \mathrm{E}-05$

$.158 E-05$

$.158 \mathrm{E}-05$

$.158 \mathrm{E}-05$

$.158 \mathrm{E}-05$

$.158 \mathrm{E}-05$

- $158 \mathrm{E}-05$

$.158 E-05$

$.431 E-06$

$.390 \mathrm{E}-06$

$.353 \mathrm{E}-06$

$.319 \mathrm{E}-06$

$.289 \mathrm{E}-06$

$.261 \mathrm{E}-06$ 
Table 9

Input Data \& Solution Comparison

for Long Irradiation

\begin{tabular}{|c|c|c|c|c|c|}
\hline Trans \# & $\begin{array}{c}\text { Solution } \\
f(20) \\
\end{array}$ & $\begin{array}{c}\text { Input } \\
\text { Function } \\
t=20 \\
\end{array}$ & $\begin{array}{l}\text { Solution } \\
T(1 / 2 \text { amp.) }\end{array}$ & $\begin{array}{l}\text { Input } \\
\mathrm{T}(1 / 2\end{array}$ & \\
\hline 1 & 2.85 & 2.77 & 55 & 53.4 & \\
\hline 2 & 2.47 & 2.51 & 69 & 68.7 & $\therefore$ \\
\hline 3 & 3.42 & 3.42 & 83 & 82.3 & \\
\hline 4 & 3.29 & 3.26 & 67 & 70.0 & 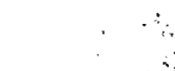 \\
\hline 5 & 2.71 & 2.72 & 63 & 62.9 & \\
\hline Means & 2.94 & 2.93 & 67. & 67.4 & \\
\hline d. Deviations & .4 & .4 & 10 & 10.5 & \\
\hline
\end{tabular}


deviations of 108 of the means. The results just reflect these distributions in the small sample size.

There is little point in performing a detailed simulation of the $3 r d$ experiment since we are able to obtain transient responses in the 2nd experiment within a few percent of the input value. To compare fission and fusion cases we are looking for a $70 \%$ difference which we will have no trouble measuring. This is provided the transient responses of the individual transistor are not very ditterent. We believe, based on our experience, that a $10 \%$ standard deviation from the mean for the transient responses errs on the positive side.

\section{Dosimetry}

Jeutron fluence measurements are uṣed in experiments only to ensure approximately the same permanent degradation of the transistors: the measurements, as such, are not used in the calculations. The requirement is for precise rather than accurate dosimetry. Fission fluences can be measured with sulphur, ${ }^{32} \mathrm{~S}(\mathrm{n}, \mathrm{p})$, dosimetery. Fusion fluences may be measured with either the ${ }^{27} A(n, \alpha)$ reaction or the ${ }^{19} F(n, 2 n)$ reaction. These three dosimetry systems have adequate precision for the experiments.

For dc irradiations a flux measurement is required. In the prediction analysis, we used a constant flux during the i.r radiation. This was only a convenience; a time dependent flux could also have been used. Again, precision rather than accuracy is a requirement. Proton recoil counters or $3 \mathrm{~F}_{3}$ counters coupled with the necessary electronics would be suitable. 


\section{Irradiation Facilities}

For the fission experiments a Fast Burst Reactor is required. Either SPRI II at SLA, or the FBR at WSMR is satisfactory. For the fusion neutrons the ICT machine at LLL will give a flux of $10^{12} \mathrm{n} / \mathrm{cm}^{2} / \mathrm{sec}$. The $14 \mathrm{MeV}$ neutron generator at University of Arkansas is expected to yeild approximately this output. Projected for completion about mid 1978 are two machines. A machine at LLL is expected to yield about $10^{13} \mathrm{n} / \mathrm{cm}^{2} / \mathrm{sec}$, while a machine at SLA is projected at double this capability. At this time, however, the presently available machines are more than adequate for the experiments.

\section{Electronic Measurements}

The device parameter measuring circuits are fairly straight forward. Figure 8 gives a circuit for the JFETS and Figure 9 a circuit for the bipolar transistors. There will probably be oscillatory problems particularly with the bipolar circuit. However, these will have to be solved on an individual basis. The output from the circuits is a voltage proportional to the required current and both circuits are driven by a constant voltage pulse. A block diagram of the complete electronic requirement is shown in Figure 10 .

The optimum timing for the train of test pulses should be determined experimentally. The pulses need to be closer together in time at the start of transient. Probably the most convenient way to do this is to program a microprocessor such as the Fairchild F8 or, alternatively, to program and step through a PROM. 


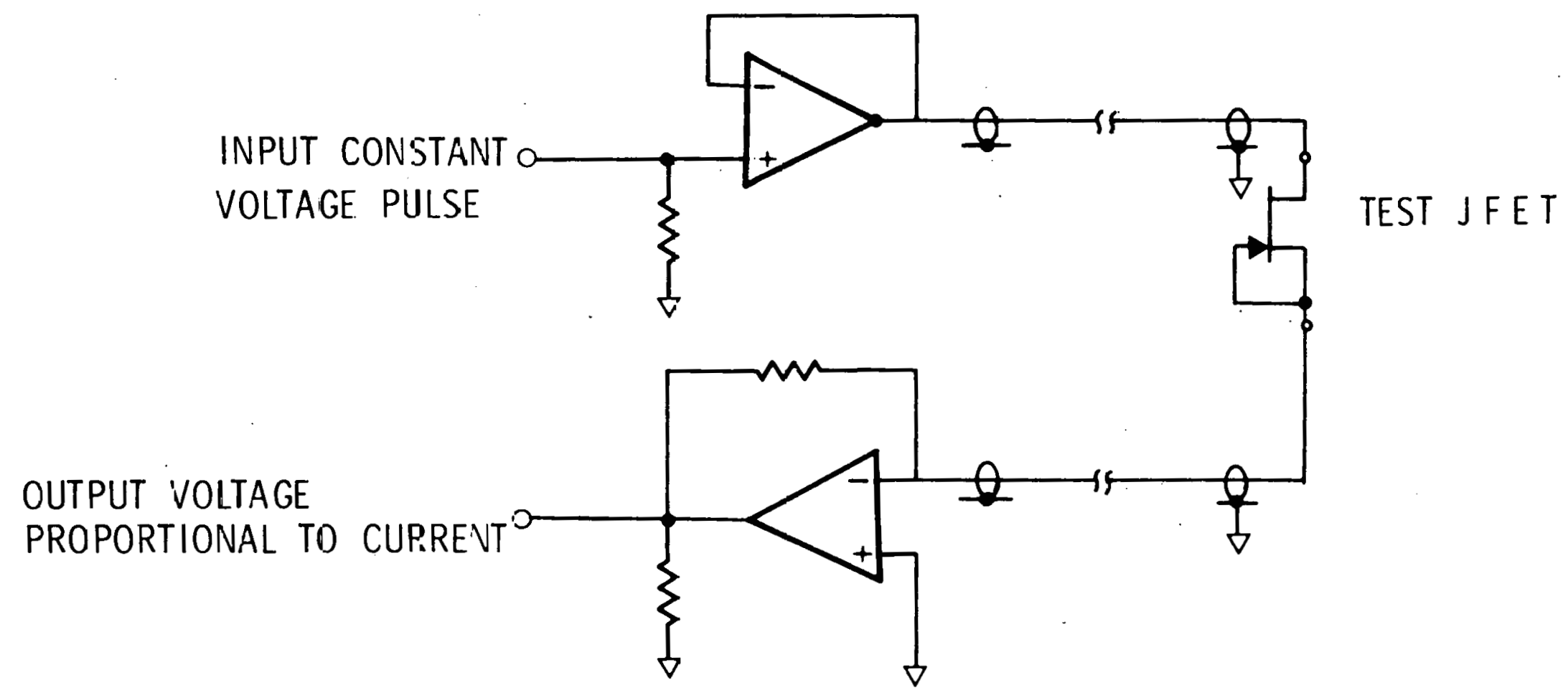

Figure 8. Test Circuits for JFErS. 


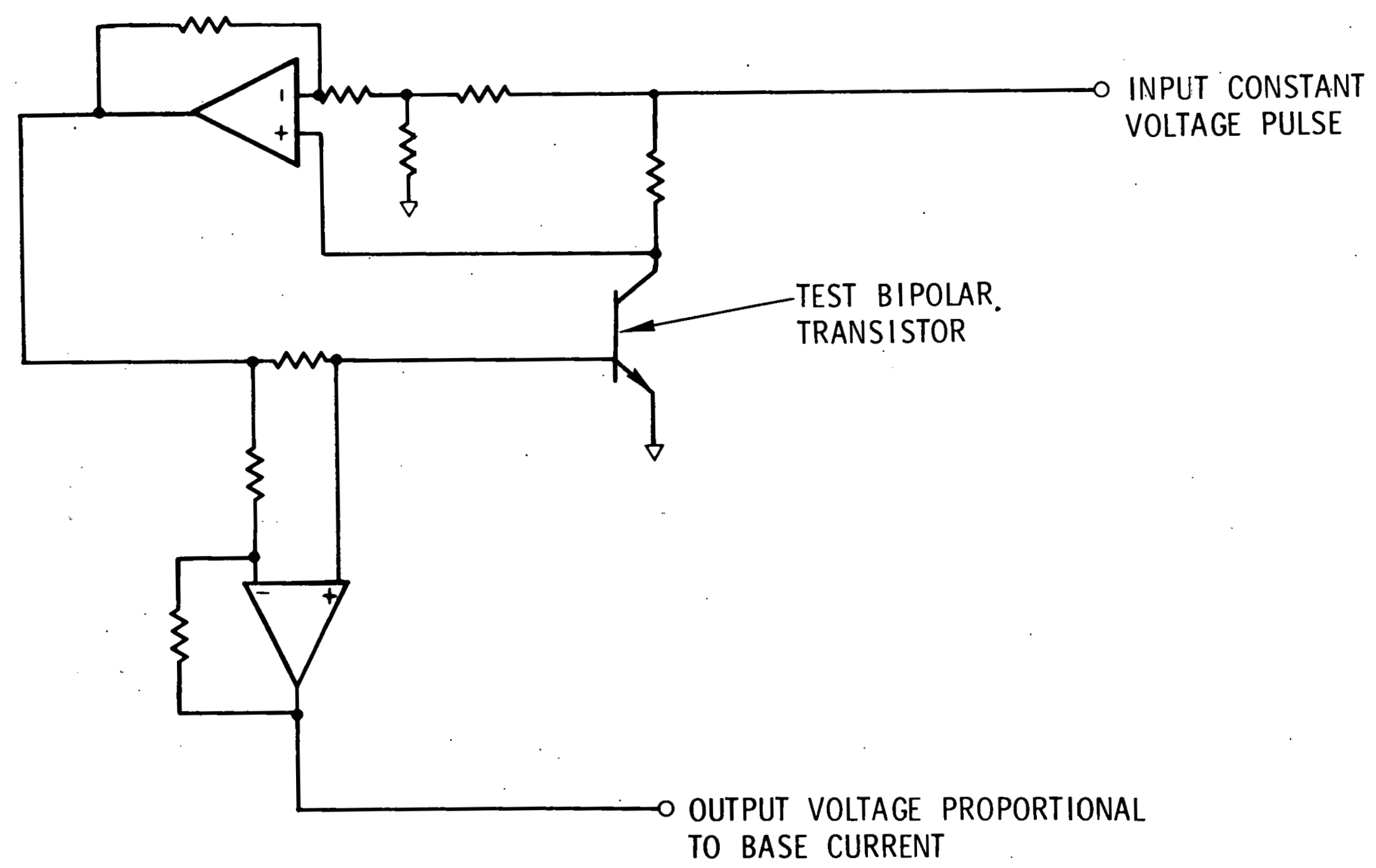

Figure 9. Test Circuit for Bipolar Transistors. 


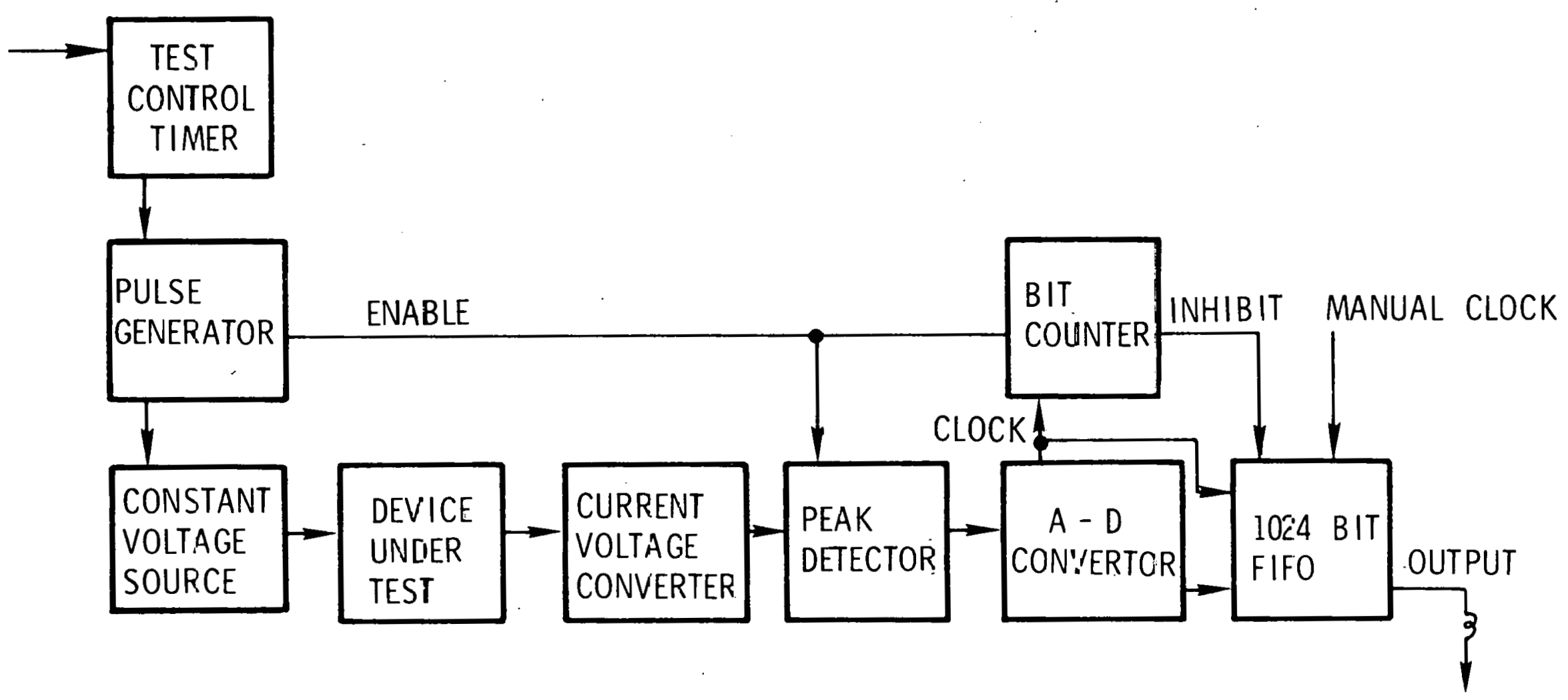

Figure 10. Block Diagram of Electronic Measuring Circuits 
One method of processing the output data is shown in Figure 10 . Other methods, from minicomputer to microprocessor to conventional pulse height analyser, are also practical. The actual method chosen will depend on the equipment available, and whether it needs to be portable, etc.

\section{Conclusions}

The analysis of the experiment shows that, although it is proposed in rather an indirect way, it is indeed very practical. The experiment will return much needed results which are directly applicable to new weapon designs as well as to stockpile systems. Here, improved data will result in more accurate hardness predictions. No new technology has to be developed to ensure the success of the experiment. The tasks to be performed are:

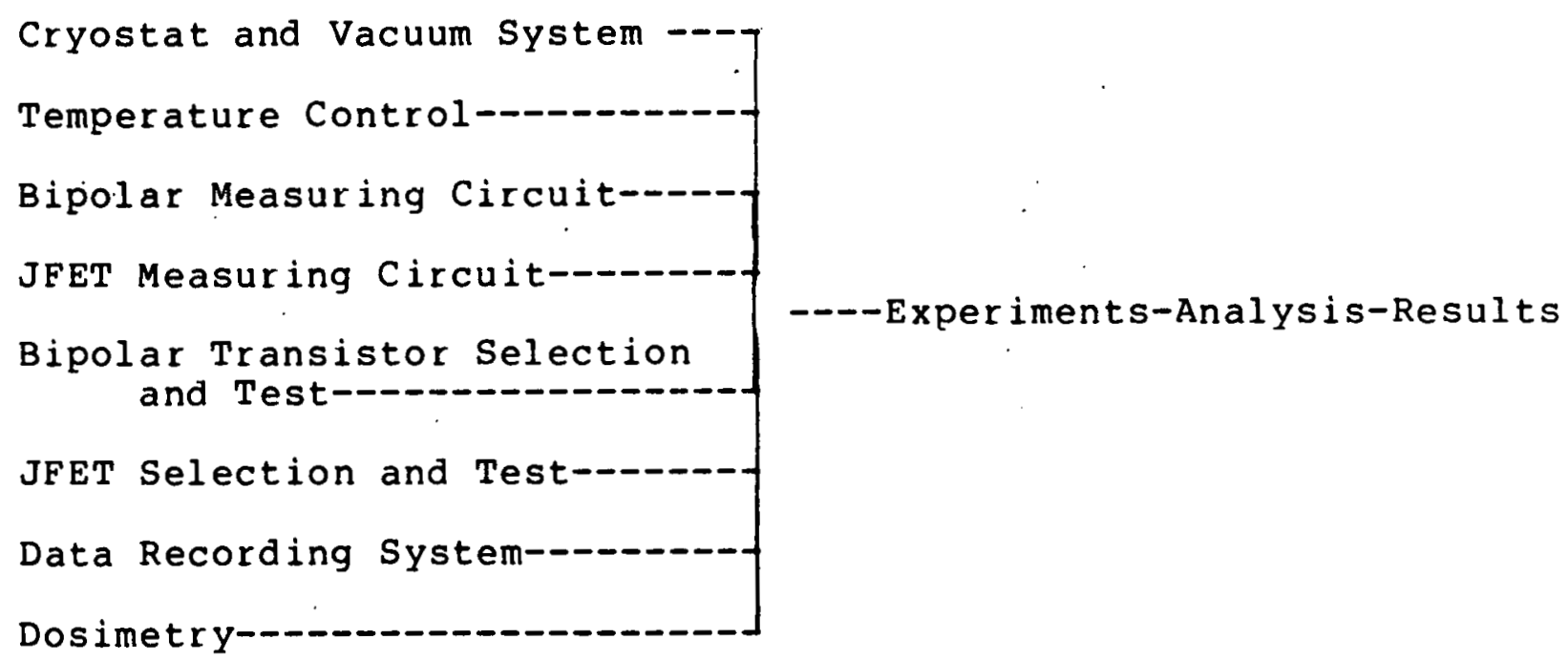

The technique of longer irradiation times and unfolding integral equations to get the transient response is also applicable to gamma ray transient annealing in metal oxide semiconductor devices. 


\section{REFERENCES}

1. Sanders, H. H. "Radiation Damage in Semiconductor Devices," SC-N-71 0887, Sandia Laboratories, March 1972, Chapter 21, pp 819-56.

2. Molander, R. C.. Wikner, E. G. DASA 2125 Institute for Defense Analyses Research Paper, 1968, p 408 .

3. Holmes, R. R., Wilson, D. K., and Blair, R. R., Faper presented at the IEEE Conference on Nuclear and Space Radiation Effects, Durham, N.H., July 1971.

4. Srour, J.R. and Curtis, O. L., "Short-Term Annealing in

Silicon Devices Following Pulsed 14 MeV Neutron Irradiation," IEEE Trans. Nuc. Sci., NS 19 No. 6., Dec 72, pp 362-70. 
Distribution:

Capt. R. R. Davis

DNA

Washington, DC 20305

Dr. E. E. Conrad

DNA

Washington, DC 20305

R. L. Pease

NWSC

Crane, IN

Dr. J. I. Meason

University of Arkansas

Fayettevilie, AR

H. L. Wright

STEWS-TE-AN WSMR

White Sands, NM 88002

Dr. N. D. Wilsey

Code 6601

NRL

Washington, DC 20375

Dr. E. A. Wolicki

Code 6627

NRL

Washington, DC 20375

Dr. W. Bendel

Code 6624

NRI

Washington, DC 20375

1751 J. M. McKenzie (10)

2141 H. H. Sander

2141 G. F. Derbenwick

2642 R. E. Jones

2642 M. R. Scott

4310 J. A. Hood

4312

4312

4312

4312

4312

5231
5231

5400

5430

5431

8266

3141

3151

ERDA/TIC (25)

(3171-1 R. P. Campbel1)
(5)

C. A. Pepmueller

W. I. Garner (3)

For ERDA/TIC

A. W. Snyder

R. M. Jefferson

R. E. NickelI

E. A. Aas (2)

(3)

(1)

